\title{
PEDAGOGÍA INCLUSIVA EN EDUCACIÓN PRIMARIA: ¿CÓMO EVALÚA EL PROFESORADO?
}

Inclusive Pedagogy in Primary Education: ¿How does the faculty assess?

Pedagogia Inclusiva no Ensino Primário: Como é que os professores avaliam?

\section{Inmaculada Concepción Orozco Almario (1)}

(1) Universidad de Sevilla, España. Teléfono: +34955420601. Correo electrónico: iorozco@us.es

\section{Resumen}

Esta comunicación pertenece a una investigación más profunda y expone desde las voces de veinticinco docentes que desarrollan una pedagogía inclusiva en Educación Primaria, cómo evalúan el aprendizaje de todo su alumnado y qué herramientas emplean en su práctica. La metodología ha sido cualitativa, con un diseño multicaso, utilizando como técnica de recogida de datos la entrevista semi-estructurada. Los resultados desvelan que evaluar sirve para mejorar los procesos educativos y algunas técnicas que caminan en este sentido son la observación, las aplicaciones tecnológicas o las rúbricas. Las conclusiones muestran algunas prospectivas y resaltan como este trabajo puede ser útil para otros profesionales.

Palabras clave: Pedagogía inclusiva; Educación Primaria; profesorado; evaluación

\begin{abstract}
This communication belongs to a deeper investigation and exposes from the voices of twenty-five teachers who develop an inclusive pedagogy in Primary Education, how they evaluate the learning of all their students and what tools they use in their practice. The methodology has been qualitative, with a multicaso design, using as a data collection technique the semi-structured interview. The results reveal that evaluation serves to improve educational processes and some techniques that walk in this direction are observation, technological applications or rubrics. The conclusions show some prospects and highlight how this work can be useful for other professionals.
\end{abstract}

Keywords: Inclusive pedagogy; Primary Education; faculty; assessment 


\section{Resumo}

Esta comunicação pertence a uma investigação mais profunda e expõe as vozes de vinte e cinco professores que desenvolvem uma pedagogia inclusiva na Educação Primária, sobre a forma como avaliam a aprendizagem de todos os seus alunos e que ferramentas utilizam na sua prática. Foi utilizada uma metodologia qualitativa, com um desenho multicaso, utilizando como técnica de recolha de dados a entrevista semiestruturada. Os resultados revelam que a avaliação serve para melhorar os processos educativos e algumas das técnicas que caminham nesta direção são a observação, as aplicações tecnológicas ou as rubricas. As conclusões mostram algumas perspetivas e destacam como este trabalho pode ser útil para outros profissionais.

Palavras-chave: Pedagogia inclusiva; Educação Primária; professores; avaliação

\section{Introducción}

Desde el enfoque de la pedagogía inclusiva, el profesorado no puede ser cómplice de la exclusión a través de las calificaciones, sino que debe brindar oportunidades para que todos sus estudiantes se sientan responsables de su aprendizaje, participen y tengan éxito en la vida del aula, sin excepción (Florian, 2014). Tener éxito y progresar en el ámbito de la evaluación, como indican Florian y Beaton (2018), supone actuar y utilizar herramientas que permitan conceptualizar la educación como mecanismo de relación y encuentro, donde las voces del alumnado juegan un papel clave en la mejora de la práctica docente.

Por tanto, los niños y las niñas en lugar de ser sujetos a evaluar son agentes activos y toman serias decisiones en las clases y hacen posible transformar lo que ocurre dentro de un sistema (Bourke, 2016). A lo largo de esta comunicación se pretende mostrar cómo evalúa y qué instrumentos emplea el profesorado de Educación Primaria que desarrolla una pedagogía inclusiva.

\section{Método}

Se ha empleado un proceso de inducción haciendo uso de la metodología de estudios multicaso (Stake, 2006), con un diseño cualitativo. Para acceder a los participantes se acordaron reuniones con asesores de Educación Primaria del Centro de Profesorado de la provincia de Sevilla para que ofrecieran contactos de docentes inclusivos a partir de 
una serie de características dadas: confía en las capacidades de todos; utiliza metodologías activas; se preocupa por el bienestar de su alumnado, etc. Después, se utilizó la técnica de muestreo por bola de nieve (Cohen, Manion, \& Morrison, 2000), obteniendo finalmente veinticinco docentes de los seis cursos de dicha etapa (6-12 años). De estos, 18 eran mujeres (72\%) y 7 hombres $(28 \%)$, con una edad media de 43,96 años.

Los datos que se presentan forman parte de una investigación más amplia. Se elaboró un guion de entrevista semi-estructurada basada en las aportaciones de Florian (2014), Florian y Beaton (2018), Gale, Mills y Cross (2017) y Rouse (2009). En esta ocasión se expondrán algunos resultados de cuáles fueron sus acciones, centrándonos en las cuestiones dirigidas a cómo evalúa este profesorado: 1) ¿Cómo evalúa el aprendizaje de todo su alumnado?, 2) ¿qué tipo de instrumentos emplea? y ¿por qué?

El registro de los datos se realizó cara a cara a través de una grabadora, y una vez trascrita la información, se hizo una devolución por participante. La privacidad y confidencialidad del profesorado fue mediante consentimientos informados $y$ seudónimos.

Por último, a través de un análisis cualitativo se creó un sistema de categorías y códigos (Miles \& Huberman, 1994). Las transcripciones fueron introducidas en MAXQDA 12. El código utilizado fue "evaluación".

\section{Resultados}

Para el profesorado la evaluación era un proceso que suponía mirarse a sí mismo como profesional y repensar la praxis educativa. Todos empleaban un amplio abanico de instrumentos porque recurrir a una única herramienta como un examen implicaba segregar, generar malestar, obviar los estilos de aprendizaje y limitar la capacidad de sus estudiantes.

Claudia: Tú tienes que conocer cómo aprenden y cuáles son sus motivaciones, y para eso, yo no necesito una prueba escrita. Es innecesario someter a los niños a ese estrés.

Por un lado, hacían uso de la observación diaria. A través de las miradas y la reflexión compartida sobre lo que ocurría en el aula junto al alumnado podían ayudarle en el proceso y recoger, al mismo tiempo, una información real de qué y cómo aprendía. 
Macarena: Para mí la observación, compartir, estar en el aula con ellos, darle voz y que ellos te devuelvan, es suficiente.

Otros incorporaban aplicaciones tecnológicas como Idoceo, Plyckers, Kahoot y ClassDojo para que cada uno interactuara con su grupo de iguales, disfrutara de las asignaturas a través del juego y superara los retos sin miedo al error.

Carmen: Si todo lo haces a través de un control, tú no estás atendiendo a la diversidad, entonces con estas aplicaciones te das cuenta como los niños saben contenidos, aunque no sean capaces de escribirlos.

Por otra parte, algunos docentes usaban las rúbricas para que los estudiantes llevaran a cabo un trabajo de metacognición, conocieran cuáles eran sus objetivos y cómo podían dar el máximo de sí mismos. No obstante, no se trataba de rúbricas ya elaboradas, sino que estas iban construyéndose a través del diálogo con ellos.

Patricia: Ahora estoy en ese proceso de reelaborar mis propias rúbricas, dárselas a conocer a ellos y que ellos, digamos, las hagan suyas. Para ellos es muy importante porque se le da voz.

En definitiva, para estos profesionales, la evaluación no es un acto de opresión y clasificación, sino situaciones de encuentro, cooperación y humanización encaminados hacia la mejora de los procesos de enseñanza-aprendizaje.

Ángel: La evaluación no es tanto como “este niño es capaz de...”, sino qué niños pueden ayudar a otros. Yo no soy capaz de decir qué niño es válido o no, creo que forma parte de la dignificación de nuestro trabajo.

\section{Conclusiones}

Se espera que las voces del profesorado contagien a otros docentes que deseen apostar por una evaluación más justa, democrática y accesible en las escuelas. En futuras investigaciones este estudio se complementará con observaciones en el aula y entrevistas al alumnado.

\section{Referencias}

Bourke, R. (2016). Liberating the Learner Through Self-assessment. Cambridge Journal of Education, 46(1), 97-111.

Cohen, L., Manion, L., \& Morrison, K. (2000). Research Methods in Education. London: Routledge. 
Florian, L. (2014). What counts as evidence of inclusive education? European Journal of Special Needs Education, 29(3), 286-294.

Florian, L., \& Beaton, M. (2018). Inclusive pedagogy in action: getting it right for every child. International Journal of Inclusive Education, 22(8), 870-884.

Gale, T., Mills, C., \& Cross, R. (2017). Socially Inclusive Teaching: Belief, Design, Action as Pedagogic Work. Journal of Teacher Education, 68(3), 345-356.

Miles, M., \& Huberman, A. (1994). Qualitative data analysis. Thousand Oaks, C.A: Sage Publications.

Rouse, M. (2009). Developing inclusive practice: A role for teachers and teacher education. Education in the North, 16, 6-13.

Stake, R. (2006). Multiple Case Study Analysis. New York: The Guilford. 